\title{
IDENTIFICATION OF THE FUEL ROD CLADDING DESTRUCTION FROM THE CHANGE OF THE SNF STORAGE CASKS RADIATION
}

\author{
V.G. Rudychev ${ }^{1 *}$ N.A. Azarenkov ${ }^{1}$, I.O. Girka ${ }^{1}$, Y.V.Rudychev ${ }^{2,1}$ \\ ${ }^{1}$ V. N. Karazin Kharkiv National University, 61022 Kharkiv, Ukraine; \\ ${ }^{2}$ National Science Center "Kharkiv Institute of Physics and Technology", 61108 Kharkiv, Ukraine
}

(Received July 20, 2020)

\begin{abstract}
Two options for changing the distribution of spent nuclear fuel due to the possible destruction of the cladding of fuel rods, which causes a change in radiation outside the cask, are considered for VSC-24 casks used for storage of spent nuclear fuel by the dry method. The effect of height reduction due to the destruction of the fuel rods of all 24 SFAs and 10 central SFAs on external radiation is studied analytically and by numerical modeling in the MCNP package. The destruction of $24 \mathrm{SFA}$ is shown to lead to a significant decrease in the dose rate of neutrons and gamma-radiation from ${ }^{60} \mathrm{Co}$ on the weather lid of the cask, and of gamma-radiation from SNF isotopes at the mid-height of the side surface of the cask. The destruction of the ten central SFAs can be determined only from a change in the neutron radiation in the air inlets of the cask.
\end{abstract}

PACS: 28.41.Ak, 28.41.Kw, 28.41.Qb, 28.41.Te

\section{INTRODUCTION}

The spent nuclear fuel (SNF) management and recycling is one of the urgent problems of up-to-date atomic power engineering. Currently, the delayed interim SNF storage by dry method for the period up to fifty years or more is employed in most of the countries, which operate nuclear power plants (NPPs). The technology of storage in casks with SNF cooling by naturally convected ambient air is the most widely used one. The spent fuel is loaded into metal baskets filled with inert gas, and these baskets are placed in a shielding concrete or metal cask. The massive thick-walled structure of the cask body provides, first of all, radiation shielding, and also prevents the basket from the mechanical damages under probable external actions. The SNF, loaded into the basket, generates a significant amount of heat induced by the decay of fission products and actinides. This heat is vented by natural convection of the ambient air, which enters the vent holes of the cask and flows around the basket surface. In this case there are some restrictions on heat release for different cask designs, which depend on the number of spent fuel assemblies (SFA), burnup, and SNF cooling time. As a rule, the heat release power of one SFA of WWERtype reactor is $1 \mathrm{~kW}$ for SNF with the burnup level of $35 . .45 \mathrm{MW} \cdot$ day $/ \mathrm{kg} \mathrm{U}$ and cooling time for more than 5 years [1]. Such a restriction provides the temperature $\approx 300^{\circ} \mathrm{C}$ inside the basket filled with SFA under normal operation for various cask designs [2]. Since the SNF storage is a long term process, intended for decades, and the heat release decreases with time rather slowly, then SFAs are stored for a long time at relatively high temperatures. At SNF long-term storage, the destruction of both the fuel rod claddings and the SFA spacing fence is possible with the subsequent SNF spilling out to the bottom of the sealed storage basket. Chemical and thermal interaction of SNF with the metal (steel) of the basket can destroy the latter, what can cause the release of radionuclides into the environment. At present, there are no techniques for monitoring the possible destruction of the claddings with subsequent SNF spilling to the bottom of the storage basket. Monitoring the temperature of the air, that leaves the cask, and comparing it with the ambient temperature do not make it possible to determine the variation in the geometric configuration of the heat source, as long as it depends on the heat release of the entire SNF volume [5]. Also, there are no methods, based on other physical principles, for monitoring the possible fuel rod cladding destruction with a subsequent SNF spilling out.

The objective of the present paper is to study the external radiation characteristics at the change of the radiation source geometric configuration, caused by possible destruction of the fuel rod claddings and SNF spilling to the bottom of the sealed basket of the storage cask.

\section{SIMULATION OF THE RADIATION SOURCE}

The dose rate of the external radiation, generated by $\gamma$-quanta or neutrons, is known to be determined,

*Corresponding author E-mail address: rudychevv@gmail.com 
at a fixed activity of the radiation sources inside the object, by geometric configuration of the radiating object. The variation in the radiation flux on the axis and at the base of the cylindrical non-absorbing sources with a fixed total activity and varying height of the cylinder is studied as an example (Fig.1).
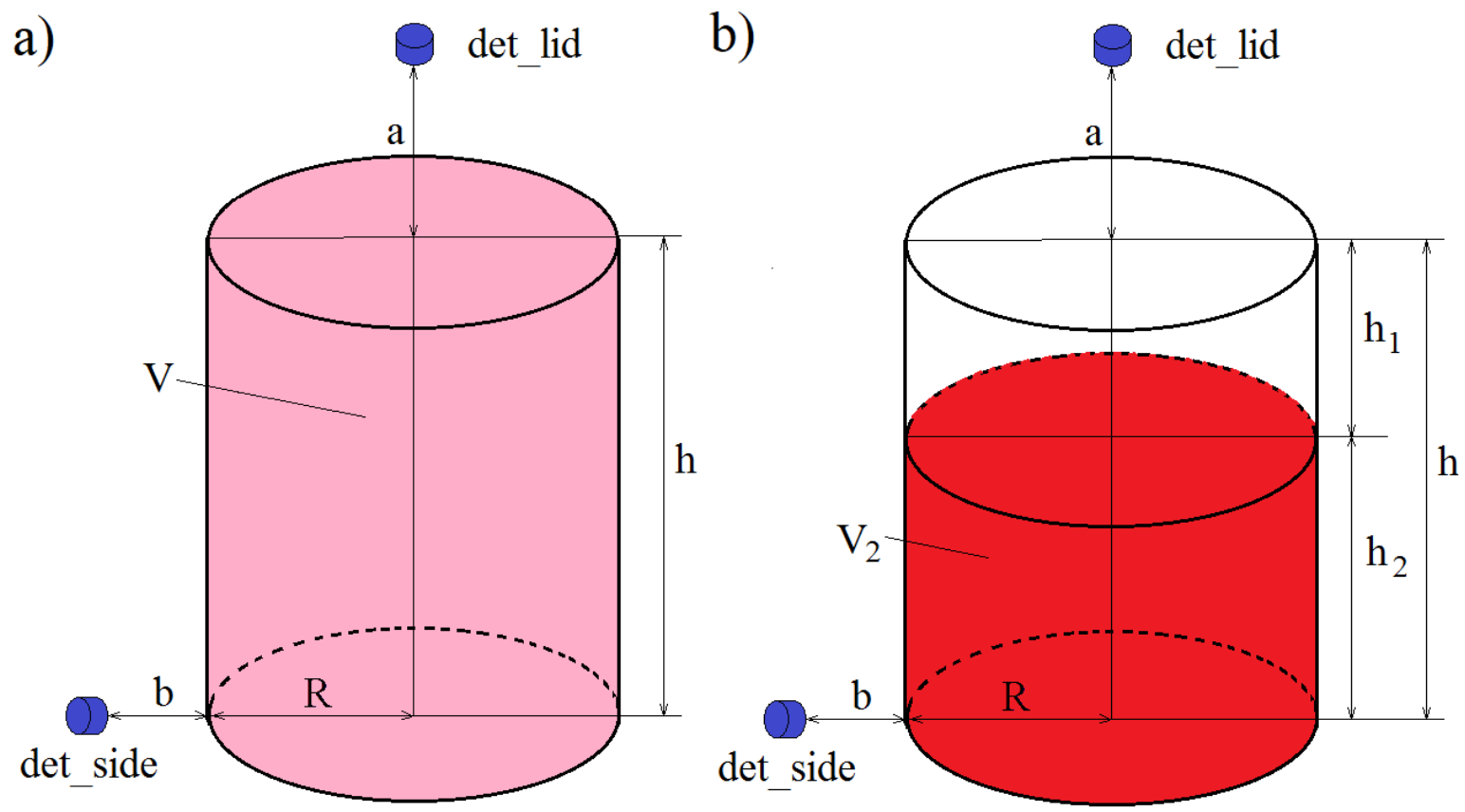

Fig.1. Layout of the detectors on the cylindrical source with the height $h$ and $h_{2},(a)$ and (b), respectively

The radiation flux $I_{a c}(a, h)$ at the distance a from the cylindrical non-absorbing source in the axial direction (the respective detector is indicated as "det_lid" in Fig.1,a) is determined by the integration of point sources over the cylinder volume with height $h$ and radius $R$. This integral has the following form $[6]$ :

$$
I_{a c}(a, h)=\rho_{\text {sour }} \cdot \int_{0}^{h} d z \int_{0}^{R} \frac{2 \pi, r d r}{r^{2}+(z+a)^{2}},
$$

where $\rho_{\text {sour }}$ is the density of the point radiation sources in the cylinder. If the cylinder height decreases from $h$ to $h_{2}$ (see Fig.1,b) for fixed total ac- tivity of the point radiation sources, then the ratio of the radiation flux in the case of the cylinder height $h_{2}$ to that in the case of the cylinder height $h$ is determined by the following relation:

$$
\operatorname{Rat}_{a c}\left(h, h_{2}\right)=\frac{h \cdot I_{a c}\left(a+h_{1} h_{2}\right)}{h_{2} \cdot I_{a c}(a, h)} .
$$

The radiation flux $I_{r a}(b, h)$ at the distance $b$ from the surface of the cylindrical non-absorbing source with height $h$ and radius $R$ in the radial direction at the level of the cylinder base (the respective detector is indicated as "det_side" in Fig.1,a) is determined by the following expression[6]:

$$
I_{\text {rad }}(b, h)=\rho_{\text {sour }} \cdot \int_{0}^{h} d z \int_{0}^{R} \frac{2 \pi r d r}{r^{4}+2 r^{2} \cdot\left(z^{2}-b^{2}\right)+\left(z^{2}+b^{2}\right)^{2}} .
$$

If the cylinder height deceases from $h$ to $h_{2}$ (see Fig.1,b) for the fixed total activity of the point radiation sources, then the radiation flux for the case of the cylinder height $h_{2}$ to that in the case of the cylinder height $\mathrm{h}$ can be calculated from the following relation:

$$
\operatorname{Rat}_{\text {rad }}\left(h, h_{2}\right)=\frac{h \cdot I_{\text {rad }}\left(b, h_{2}\right)}{h_{2} \cdot I_{\text {rad }}(b, h)} .
$$

The ventilated cask VSC-24, used for dry storage at Zaporizhzhya NPP, has been upgraded and adapted to the hexagonal SFAs of WWER-1000 reactors [7] The parameters of this particular cask are used in the present paper to study the changes in the external radiation flux in case of possible destruction of the fuel rod claddings. Structurally, the VSC-24 comprises a concrete ventilated cask with a sealed cask basket, loaded with twenty-four SFAs. The steel basket wall with thickness of 2.5 and the $7.5 \mathrm{~cm}$ thick ferrule, as well as the concrete body of the cask with the thickness of $70 \mathrm{~cm}$, in the aggregate serve as the radiation shielding in the radial direction. The shielding in the axial direction is provided by the steel structural and force covers of the basket, the weather lid of the cask with the total thickness of over $40 \mathrm{~cm}$, as well as by the neutron hydrogen-containing plate, made of 
RX-277 material, with the thickness of $5 \mathrm{~cm}$.

The MCNP package [3] was used to calculate the characteristics of radiation ( $\gamma$-quanta and neutrons) outside the cask. Fig.2 presents the model of VSC-24 cask, generated in MCNP, with the radiation detectors arrangement taken into account. The detector (see indicated as "Lid detector" in Fig.2) is placed in the axial direction on the cask weather lid. Radial detectors (see indicated as "Side detector" in Fig.2) are placed in the radial direction on the cask surface at different heights.

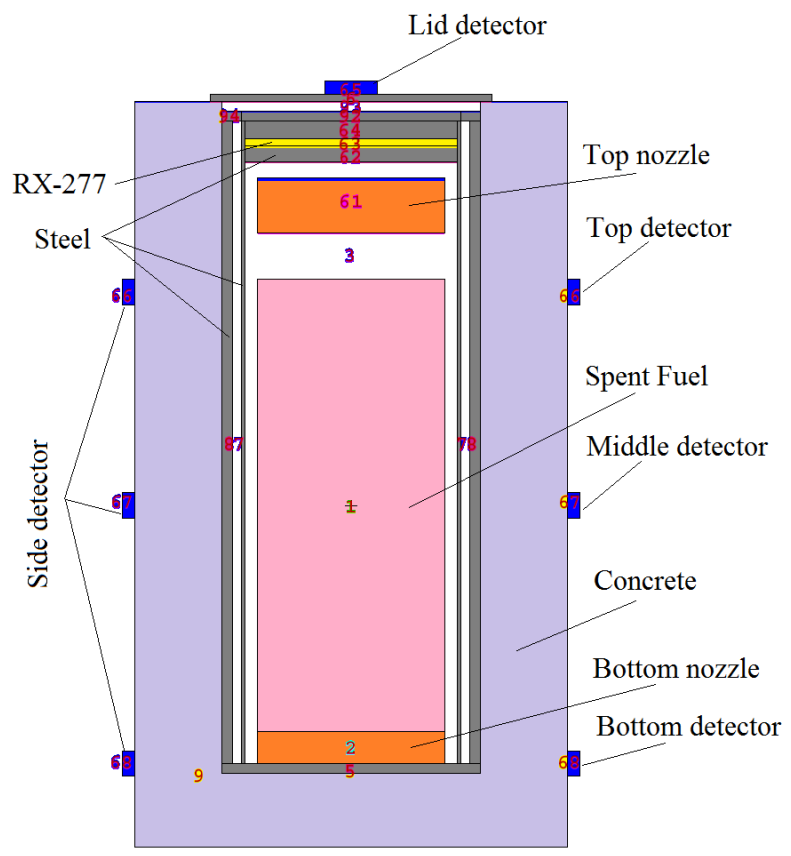

Fig.2. Visualization of the geometry model of VSC24 cask in section plane $p x=+0.0 \mathrm{~cm}$, generated in MCNP package

In the geometry model, shown in Fig.2, the air inlets and outlets are filled with concrete to apply a conservative approach to determination of the changes in the radiation characteristics. A model of the cask with the ducts, through which cooling air enters inside, is developed to determine the radiation characteristics at the air inlets. Fig. 3 presents the isometric projection of the VSC- 24 cask model with air ducts, which is generated in MCNP package. The radiation detectors are placed at the air inlets.

SNF, as the source of radiation, is simulated by twenty-four SFAs with heads and tails. It was shown in [7] that, when simulating radiation from each of the 24 SFAs for the VSC-24 WWER-1000 and radiation from the homogenized SNF region, the calculations results for the external radiation (for both $\gamma$-quanta and neutrons) differ by only $2 \ldots 3 \%$. Therefore, the radiation source from 24 SFAs is simulated in the present paper in the form of a zone, in which spent fuel is placed (fuel rods are zirconium shells filled with uranium dioxide, decay products and actinides), as well as two zones with induced activity caused by ${ }^{60} \mathrm{Co}$ in steel heads and tails. That is why the following two options are considered below. Op- tion I: only fuel rod claddings are destroyed, without destruction of the SFA supporting elements, with further SNF spilling to the bottom of the storage basket, so that the heads (indicated as TN in Fig.4) remain in the upper position. Option II: the fuel rod claddings are destroyed together with SFA bearing elements, what is followed by SNF spilling to the bottom of the storage basket and displacement of the heads down (see indicated as TNII in Fig.4) from the upper position. Since the temperature of the central SFAs is higher [2], the probability of the fuel rod cladding destruction in such assemblies is also higher.

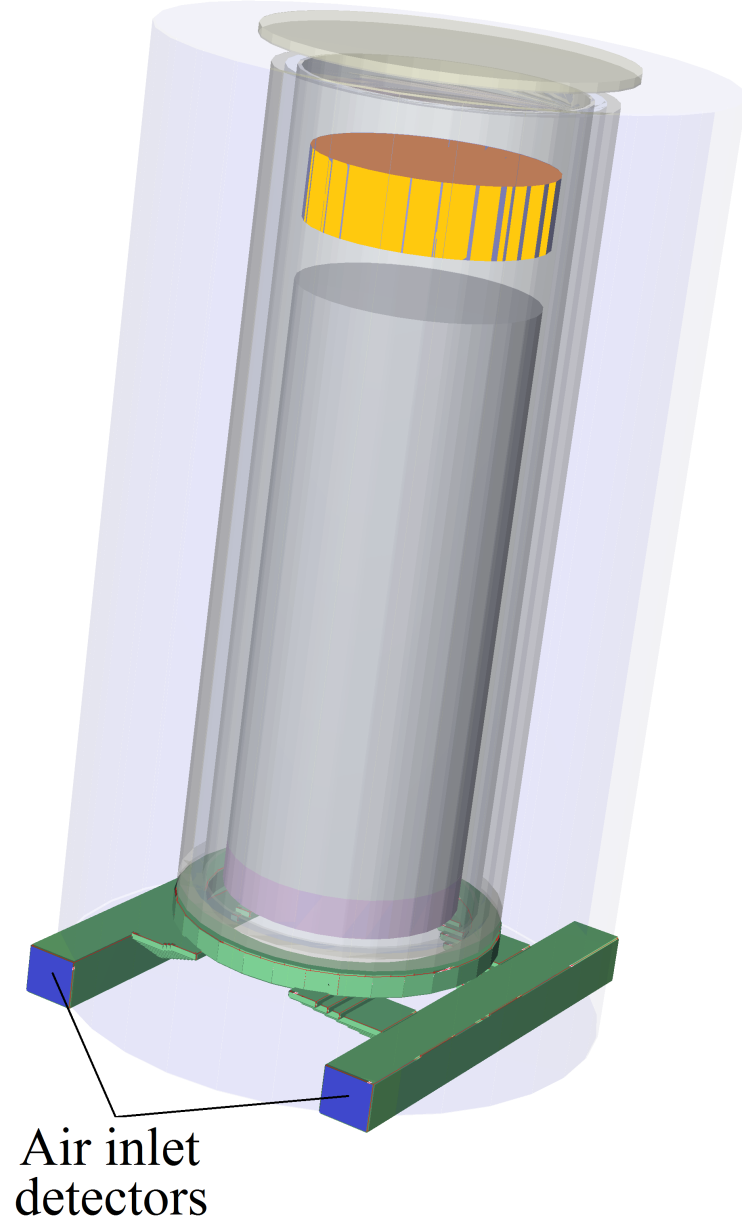

Fig.3. Isometric view of the geometry model of VSC-24 cask with air inlets, generated in MCNP package

For options I and II, the possibility of the fuel rod cladding destruction for both all 24 SFAs (SF24) and for only 10 central SFAs (SF10) is considered. In the latter case the SNF characteristics in the fourteen SFAs (SF), located along the basket perimeter, are assumed to remain unchanged. Fig.4 presents the geometric layout of SFAs in the cask for the four options mentioned above, generated in MCNP.

\section{RADIATION SOURCES}

The radiation source in the VSC-24 cask is SNF with the initial fuel enrichment of $4.4 \%$, burnup of 40.5 MWt $\times$ day $/ \mathrm{t} \cdot \mathrm{U}$ after a three-year campaign in the WWER-1000 reactor. 
Gamma radiation source. The main source of $\gamma$-quanta from SNF is the primary gamma radiation of fission products and long-lived actinides. The additional gamma radiation is generated by ${ }^{60} \mathrm{Co}$, pro- duced as a result of activation of the SFA steel elements containing ${ }^{59} \mathrm{Co}$, as well as by $\gamma$-quanta generation in $(n, \gamma)$ reactions on fissile and non-fissile elements of SNF and those of SFA.
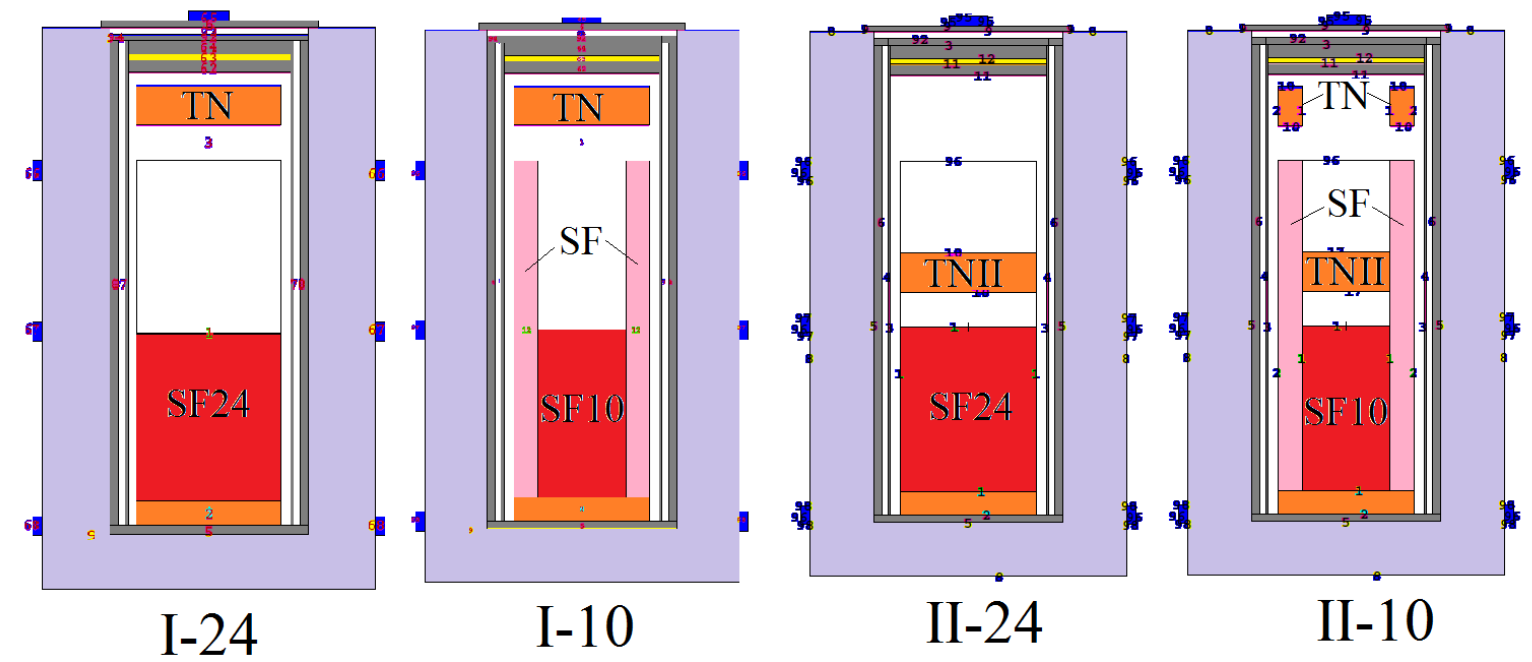

Fig.4. Geometrical layout of SFAs in a cask for four options of destruction for both the fuel rod claddings and SFA supporting elements, generated in MCNP

To determine the external radiation during storage of SNF with the given parameters such as: enrichment, fuel type, burnup level and exposure time, the spectral composition of primary $\gamma$-quanta and neutrons is calculated. Such a calculation is carried out using the SAS2H module of SCALE 5.1 package. In such package the standard SCALE 18-group gamma library is usually used, originally based on the OGRE point-data library [10]. The obtained data are taken as the source data when calculating the dose loads outside the storage casks, commonly used, the Monte Carlo method [11] in codes like MCNP or PHITS $[3,4]$. In our case, it is necessary to analyse the change in the external radiation characteristics in different places of the cask body in dependence on the SNF storage time. Therefore, the determination of the primary characteristics of SNF radiation subject to the storage time, with subsequent calculation of external radiation, is inefficient.

Dry storage is applied, as a rule, to SNF with the storage for more than three years. At such a stor- age period, the activity of short-lived isotopes with a relatively high energy of $\gamma$-quanta (more than 1 $\mathrm{MeV}$ ) can already be neglected. In this case, the main contribution to the dose rate outside the cask is made by primary $\gamma$-quanta from the fission products of SNF [12]: ${ }^{90} \mathrm{Y}\left({ }^{90} \mathrm{Sr}\right),{ }^{106} \mathrm{Rh}\left({ }^{106} \mathrm{Ru}\right),{ }^{134} \mathrm{Cs}$, ${ }^{137 m} \mathrm{Ba}\left({ }^{137} \mathrm{Cs}\right),{ }^{144} \operatorname{Pr}\left({ }^{144} \mathrm{Ce}\right),{ }^{154} \mathrm{Eu}$, and also by the induced activity of ${ }^{60} \mathrm{Co}$. The contributions of these seven $\gamma$-emitters, having different half-lives, allow determining the characteristics of photon radiation on the outer surface of the cask radiation shielding subject to the storage time. Table 1 presents the basic characteristics of these isotopes: half-lives $\mathrm{T}_{i z}$, energies of $\gamma$-quanta, whose quantum yields are more than $5 \%$ of the total yield $\mathrm{Y}_{i z}$, and activity $\mathrm{A}_{i z}$ with the storage time in the cooling pool at the reactor of three years [9]. The contribution of $\gamma$-quanta from reactions $(n, \gamma)$ to the external radiation is much smaller than that from the fission products and emitters with induced activity [11].

Table 1. Characteristics of the main isotopes and quantum yields per $1 \mathrm{~Bq}$

\begin{tabular}{|c|c|c|c|c|}
\hline Isotope & $\begin{array}{c}\mathrm{T}_{i z} \\
(\text { year })\end{array}$ & $\begin{array}{c}\mathrm{E}_{\gamma}, \mathrm{MeV} \\
(\text { year } / 1 \mathrm{~Bq}>5 \% \text { total })\end{array}$ & $\begin{array}{c}\mathrm{Y}_{i z}, \text { yield/1 Bq } \\
\text { total }\left(\mathrm{E}_{\gamma}>0.2 \mathrm{MeV}\right)\end{array}$ & $\begin{array}{c}\mathrm{A}_{i z} \text { acti- } \\
\text { vity, Bq/tU }\end{array}$ \\
\hline${ }^{60} \mathrm{Co}$ & 5.27 & $1.17(0.999) ; 1.33(0.9998)$ & 2 & \\
\hline${ }^{90} \mathrm{Y}\left({ }^{90} \mathrm{Sr}\right)$ & 28.5 & $1.76(0.00016)$ & 0.00016 & $3.26 \cdot 10^{15}$ \\
\hline${ }^{106} \mathrm{Rh}\left({ }^{106} \mathrm{Ru}\right)$ & 1.009 & $0.51(0.207) ; 0.62(0.106)$ & 0.33 & $3.02 \cdot 10^{15}$ \\
\hline${ }^{134} \mathrm{Cs}$ & 2.06 & $0.57(0.15) ; 0.60(0.975) ; 0.8(0.851)$ & 2.224 & $2.73 \cdot 10^{15}$ \\
\hline${ }^{137 m} \mathrm{Ba}\left({ }^{137} \mathrm{Cs}\right)$ & 30 & $0.662(0.9)$ & 0.9 & $4.15 \cdot 10^{15}$ \\
\hline${ }^{144} \mathrm{Pr}\left({ }^{144} \mathrm{Ce}\right)$ & 0.778 & $0.697(0.013) ; 1.49(0.0028) ; 2.19(0.0071)$ & 0.0235 & $3.77 \cdot 10^{15}$ \\
\hline${ }^{154} \mathrm{Eu}$ & 8.6 & $0.6(0.061) ; 0.72(0.2) ; 0.87(0.115) ; 1.0(0.28) ; 1.27(0.355)$ & 1.22 & $3.86 \cdot 10^{14}$ \\
\hline
\end{tabular}


Neutron source. The spontaneous fission of actinides contained in SNF is the main source of neutrons. The additional contribution is made by the neutrons, produced as a result of the interaction of $\gamma$-particles emitted by SNF actinides in the reaction $(\alpha, \mathrm{n})$. Namely, the spontaneous fission of ${ }^{244} \mathrm{Cm}$ with half-life of 18.1 years is the main source of neutrons (about 97.4\%). And also about $0.8 \%$ of neutrons are produced by ${ }^{240} \mathrm{Pu}$ and ${ }^{242} \mathrm{Pu}$ [13]. About $1.7 \%$ of neutrons are produced in the interaction of $\alpha$-particles, emitted by SNF actinides (mainly ${ }^{238} \mathrm{Pu}$, ${ }^{238} \mathrm{Pu},{ }^{244} \mathrm{Cm}$ ), with the oxygen isotope ${ }^{18} \mathrm{O}$ in the reaction $\left({ }^{18} \mathrm{O}(\alpha, \mathrm{n}){ }^{21} \mathrm{Ne}\right)$. This oxygen isotope is contained in SNF (uranium dioxide) in the amount of about $0.2 \%$. The spectrum of the neutrons produced by the spontaneous fission of actinides is similar to that from the induced fission of ${ }^{235} \mathrm{U}$, and is approximated by the following relation [14]:

$$
N(E)=\frac{2 \sqrt{E}}{\pi \theta^{3}} \exp (-E / \theta),
$$

where $\mathrm{E}$ - energy, $\mathrm{MeV}$, and $\theta$ - hardness parameter equal to $1.33 \mathrm{MeV}$ for ${ }^{244} \mathrm{Cm}$. The average energy of these neutrons is approximately equal to $1.995 \mathrm{MeV}$. The yield of neutrons from all the 24 spent fuel assemblies (SFA) loaded in the cask for the SNF with burnup of $40.5 \mathrm{MW} \cdot \mathrm{day} / \mathrm{t} \cdot \mathrm{U}$ and 3-year storage is about $3.76 \cdot 10^{9}$ neutron/s.

\section{THE COMPUTATIONAL RESULTS FOR THE EXTERNAL RADIATION CHARACTERISTICS}

\subsection{Neutrons}

The radiation shieldings of the VSC-24 cask in the radial and axial directions differ significantly for neutrons and $\gamma$-quanta. In the VSC-24 cask, the neutron flux in the radial direction is significantly attenuated by radiation shield of $70 \mathrm{~cm}$ thick concrete wall. While the radiation shield in the vertical direction is much weaker: it is provided by steel lids and a $5 \mathrm{~cm}$ thick neutron absorbing layer. The neutron dose rate $\left(\mathrm{DR}_{n}\right)$ on the cask lateral surface is by the order of magnitude lower than that produced by $\gamma$-quanta $\left(\mathrm{DR}_{\gamma}\right)$, where for VSC-24 $\mathrm{DR}_{n} \approx 0.8 \mathrm{mSv} / \mathrm{h}$, and $\mathrm{DR}_{\gamma} \approx 30 \mathrm{mSv} / \mathrm{h}$. At the same time, on the surface of the cask weather lid, $\mathrm{DR}_{n}$ is several times higher than $\mathrm{DR}_{\gamma} \mathrm{DR}_{n} \approx 82 \mathrm{mSv} / \mathrm{h}$, and $\mathrm{DR}_{\gamma} \approx 19 \mathrm{mSv} / \mathrm{h}$ [12]. This distinguishes the VSC-24 casks from the metal ones with neutron shielding of the CASTOR type, where $\mathrm{DR}_{n} \approx \mathrm{DR}_{\gamma}$ on the cask lateral surface.

When calculating in the MCNP package, the data similar to those in [15] are used, the density of homogenized SNF is assumed to be $3.5 \mathrm{~g} / \mathrm{cm}^{3}$. The partial contribution of SNF elements, with taking into account the presence of a distancing grid made of steel, is considered to be equal to the following: 0.146 for zirconium, 0.523 for uranium, 0.073 for oxygen, and 0.258 for iron. Fig. 5 presents the spectrum of primary neutrons of ${ }^{244} \mathrm{Cm}$ isotope $(\mathrm{SpW}$ curve), the spectrum of neutrons leaving the SNF zone (SurfSNF curve), and the neutron spectrum on the VSC-24 weather lid (SurfLid curve) after passing through the steel and neutron shields. The data, presented in Fig.5, illustrate a significant decrease in the energy of high-energy neutrons after passing through the radiation shield.

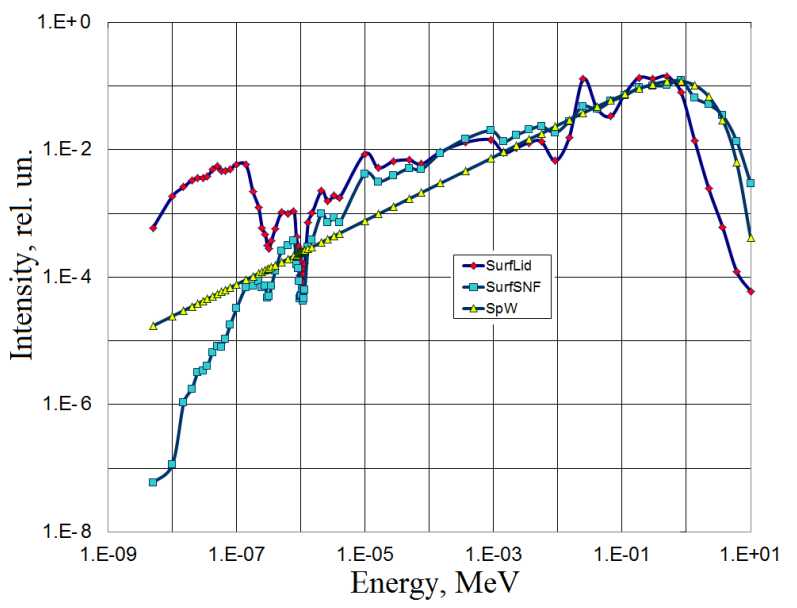

Fig.5. Transformation of the spectrum of neutrons, emitted by ${ }^{244} \mathrm{Cm}$ (SpW), on the surface of $S N F$ zone (SurfSNF) and on the weather lid of $V S C-24$ (SurfLid)

The calculations of the neutron dose rate on the weather lid and on the lateral surface are carried out for a twofold change in the volume of the SNF zone, so that the materials density in the SNF zone varied from 3.5 to $7.0 \mathrm{~g} / \mathrm{cm}^{3}$ with the fixed elemental composition ratio. Fig. 6 presents the ratios of the dose rates on the weather lid (indicated as "Lid detector"), produced by SNF without the destruction of the fuel rod claddings, to those in the case of destroyed fuel rod claddings, indicated as "DR $\mathrm{D}_{\text {destr }} / \mathrm{DR}_{\text {norm }}$ " for options I-24 (indicated by triangles) and I-10 (indicated by rectangles), subject to the degree of destruction. The $\mathrm{DR}_{\text {destr }} / \mathrm{DR}_{\text {norm }}$ ratios, determined only by change in the sources geometry according to the expression (2), are given (solid GeoLid curves) for comparison. In fact, it is the change in the geometry, i.e. the height of the entire source, comprising 24 SFAs, that determines the change in $\mathrm{DR}_{\text {destr }} / \mathrm{DR}_{\text {norm }}$ ratio. When ten central SFAs are destroyed, the configuration of the radiation source attains the shape of a cup, in this case $\mathrm{DR}_{\text {destr }}$ practically does not differ from $\mathrm{DR}_{\text {norm }}$. (see Fig.6, Option I-10). The magnitudes of $\mathrm{DR}_{\text {destr }}$ on the lateral surface are practically the same as $\mathrm{DR}_{\text {norm }}$ for Options I-24 and I-10. The ratios $\mathrm{DR}_{\text {destr }} / \mathrm{DR}_{\text {norm }}$ on the lateral surface, associated with the change in the sources geometry, are shown by dotted curves (indicated as GeoRad). The ratios $\mathrm{DR}_{\text {destr }} / \mathrm{DR}_{\text {norm }}$ in the air ducts of the cask are calculated for Options I-24 and I-10 with the source height change by $50 \%$ due to the fuel rod cladding destruction taken into account. The ratios $\left(\mathrm{DR}_{\text {destr }} / \mathrm{DR}_{\text {norm }}\right)$ for Options I-24 and I-10 are indicated by circles in Fig.6. 


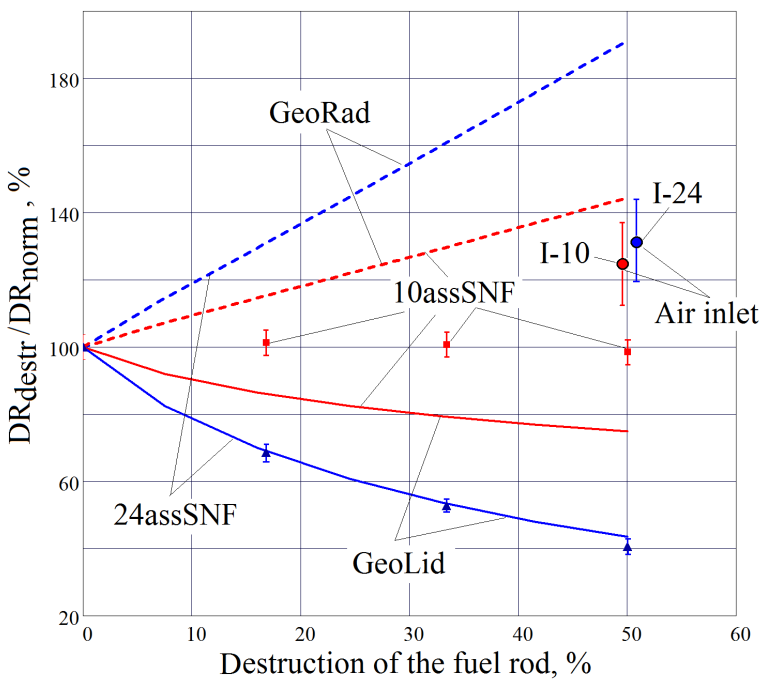

Fig.6. Ratios of $D R_{n}$ in the case of the fuel rod cladding destruction to the $D R_{n}$ in the case of normal cladding vs degree of the fuel rod destruction

Thus, it follows from the data, shown in Fig. 6, that the measurement of the DR, produced by neutrons on the weather lid of the VSC-24 storage cask, is reliable for determining the change in the height of the SNF zone due to the possible destruction of the fuel rod claddings of all 24 SFAs. When the fuel rod claddings of only 10 central SFAs are destroyed, no changes in the $\mathrm{DR}_{n}$ are observed on the weather lid. However, in this case the change in the $\mathrm{DR}_{n}$ occurs with a sufficient degree of certainty in the VSC-24 air ducts. Note, that the change in the SNF zone configuration cannot be determined by measuring the neutron flux on the VSC-24 lateral surface.

An exponential decrease in the DR with the temporal scale corresponding to the half-life of ${ }^{244} \mathrm{Cm}$ of 18.1 years would be demonstrated in the case of normal fuel rod cladding by periodical (1 or 2 times a year) measurement of the dose rate produced by neutrons on the weather lid of the VSC-24 cask. It was shown in [16] that if the measured value of DR differs from the value, which is expected on the basis of the previous measurement, than it means that the source geometric configuration has changed.

Fig. 7 shows the types of the expected DR dependences (on the weather lid and in the VSC-
24 air inlets on the SNF storage time under normal operation and at the fuel rod cladding destruction. When measuring DR once a year, it is assumed that the measured DR magnitude for the ninth year corresponds to the exponential decrease in the SNF neutron flux, and at the measurement on the tenth year of storage a stepwise decrease in DR on the weather lid and growth in the VSC-24 air inlets are observed, what indicates the change in the geometric SNF zone configuration.

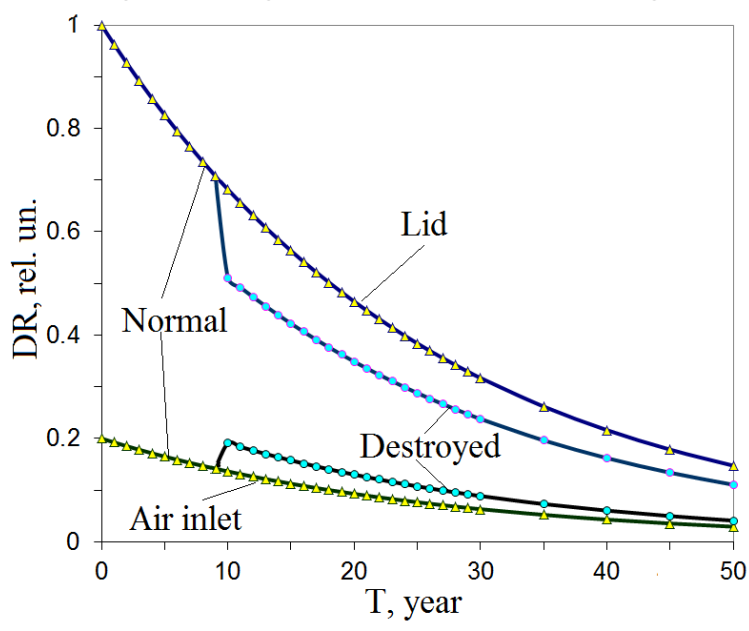

Fig.7. The expected $D R$ dependencies (in the weather lid and in the VSC-24 air) inlets on the SNF storage time under normal operation and at the fuel rod cladding destruction

\subsection{Gamma-quanta}

The source of gamma-quanta, in contrast to that of neutrons, has a number of specific features. Gammaquanta are emitted not only by the SNF zone, but also by the heads and tails of SFAs due to the induced activity. In this case, the external radiation on the lateral surface of the cask is determined by the SFAs located along the storage basket perimeter [12]. Gamma-radiation, in contrast to the neutron one, is determined by several isotopes with half-lives from $\sim 0.8$ to 30 years. Therefore, in the course of SNF storage for several years or even tens of years, the concentration of isotopes and, accordingly, their contribution to the external radiation changes significantly.

Table 2. DR magnitudes in 3 detectors placed at different height of the cask lateral surface

\begin{tabular}{|c|c|c|c|c|c|c|c|c|}
\hline Detector & $\# \#$ & $\mathrm{DR}_{i z} \cdot 10^{19}, \mathrm{~Sv} / \mathrm{s} 1 \gamma$ & ${ }^{154} \mathrm{Eu}$ & ${ }^{134} \mathrm{Cs}$ & ${ }^{137} \mathrm{Cs}$ & ${ }^{144} \mathrm{Pr}$ & ${ }^{106} \mathrm{Rh}$ & ${ }^{90} \mathrm{Y}$ \\
\hline \multirow{5}{*}{ Top det } & 1 & 24 SFA, normal & $\mathbf{4 . 3 7}$ & $\mathbf{0 . 3 6 8}$ & $\mathbf{0 . 0 6 4}$ & $\mathbf{8 8 . 4}$ & $\mathbf{1 . 6 7}$ & $\mathbf{8 4 . 9}$ \\
\cline { 2 - 9 } & 2 & 24 SFA, destroyed & 0.12 & 0.012 & 0.002 & 1.9 & 0.04 & 1.8 \\
\cline { 2 - 9 } & 3 & 10 SFA, destroyed & 4.84 & 0.407 & 0.064 & 88.2 & 1.59 & 83.5 \\
\hline Middle det & 4 & 24 SFA, normal & $\mathbf{7 . 1 7}$ & $\mathbf{0 . 6 0 9}$ & $\mathbf{0 . 0 8 2}$ & $\mathbf{1 3 5 . 8}$ & $\mathbf{2 . 5 3}$ & $\mathbf{1 3 0}$ \\
\cline { 2 - 9 } & 5 & 24 SFA, destroyed & 3.93 & 0.386 & 0.063 & 74.4 & 1.62 & 72.2 \\
\cline { 2 - 9 } & 6 & 10 SFA, destroyed & 7.31 & 0.696 & 0.064 & 137 & 2.49 & 130.2 \\
\hline Bottom det & 7 & 24 SFA, normal & $\mathbf{1 . 5 3}$ & $\mathbf{0 . 1 2 8}$ & $\mathbf{0 . 0 1 9}$ & $\mathbf{3 2 . 3}$ & $\mathbf{0 . 4 5}$ & $\mathbf{2 8 . 7}$ \\
\cline { 2 - 9 } & 8 & 24 SFA, destroyed & 1.56 & 0.086 & 0.02 & 33.1 & 0.63 & 28.6 \\
\cline { 2 - 9 } & 9 & 10 SFA, destroyed & 1.46 & 0.129 & 0.004 & 32.7 & 0.56 & 29.6 \\
\hline
\end{tabular}


Table 3 presents the magnitudes of DR, produced by ${ }^{60} \mathrm{Co}$ isotope due to the induced activity in the SFA heads, in two detectors placed on the weather lid and at the top of the cask lateral surface. The DR from the SFA heads in Middle det and Bottom det detectors on the lateral surface is by $2 \ldots 3$ orders of magnitude smaller than that in Top det. Lines 1 and 4 show the magnitudes of the DR, produced by the heads of 24 normal SFAs. Lines 2 and 5 show the magnitudes of DR produced by the heads of 24 SFAs, which are shifted together with the SNF shift, Option II-24. Lines 3 and 5 show the magnitudes of DR produced by the heads of 10 SFAs, which are shifted together with their SNF shift while 14 SFAs keep their initial position, Option II-10.

Table 3. Magnitudes of DR, produced by ${ }^{60} \mathrm{Co}$ isotope, in two detectors located on the weather lid and at the top of the cask lateral surface

\begin{tabular}{|c|c|c|c|}
\hline Detector & No & $\mathrm{DR}_{i z} \cdot 10^{19}, \mathrm{~Sv} / \mathrm{s} 1 \gamma$ & ${ }^{60} \mathrm{Co}$ \\
\hline \multirow{3}{*}{ Top det } & 1 & 24 SFA, normal & $\mathbf{8 . 5}$ \\
\cline { 2 - 4 } & 2 & 24 SFA, destroyed & 4.56 \\
\cline { 2 - 4 } & 3 & 10 SFA, destroyed & 4.78 \\
\hline \multirow{2}{*}{ Lid det } & 4 & 24 SFA, normal & $\mathbf{5 4 2}$ \\
\cline { 2 - 4 } & 5 & 24 SFA, destroyed & 371 \\
\cline { 2 - 4 } & 6 & 10 SFA, destroyed & 535 \\
\hline
\end{tabular}

The overall dose rate $\mathrm{DR}_{\text {sum }}(\mathrm{T})$ at the moment $\mathrm{T}$ is determined by the relation:

$D R_{\text {sum }}(T)=\sum_{i z=1}^{N} A_{i z} \cdot D R_{i z} \cdot Y_{i z} \exp \left(-0.693 \cdot T / T_{i z}\right)$.

The analysis of the data in Tables 2 and 3 shows that the change in the geometric characteristics of the SNF region at the destruction of all 24 SFAs is determined most reliably by the "Middle det" detector located at half-height of the source, since the radiation from the heads does not influence it. The readings of this detector, calculated from the data in Table 2 and expression (6), show a decrease in $\mathrm{DR}_{\text {sum }}$ to the level of $\sim 0.6$ from the normal one at the destruction of all 24 SFAs for the period of SNF storage from 5 to 40 years. The $\mathrm{DR}_{\text {sum }}$ on all the side detectors, with possible destruction of 10 central SFAs (Option I-10), practically does not change as compared to the dose rate produced on the detectors under normal operation. Note, that, when radiation from the SFA heads (see ${ }^{60} \mathrm{Co}$, Table 3 ) is measured by the Lid det detector, $\mathrm{DR}_{\text {sum }}$ at the shift of 10 central SFA heads (Option II-10) also practically does not change. However, when all 24 SFA heads or 10 central SFA heads (Options II-24 and II-10) are shifted, the dose rates on the Top det side detector (see ${ }^{60} \mathrm{Co}$, Table 3 ) are approximately the same, despite the difference in the geometry of the radiation sources.

On the basis of the data from Tables 1 and 2, using relation (6), the contribution of different isotopes to the dose rate at the side detectors are calculated subject to the SNF storage time. The character of the $\mathrm{DR}_{\text {sum }}$ dependence on the stor- age time for different types of the fuel rod cladding destruction is almost the same, and the contributions of the individual isotopes change slightly, as compared to those at normal operation. Fig.8 shows the contributions of the individual isotopes to $\mathrm{DR}_{\text {sum }}$, measured by the "Middle det" detector, under normal operation subject to the storage time.

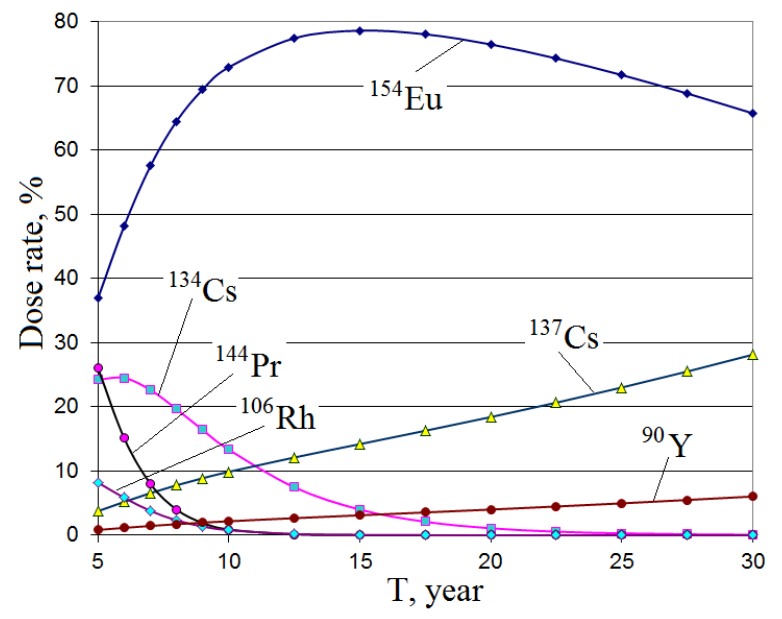

Fig.8. Contributions of individual isotopes to DR sum vs the storage time

It follows from the data, presented in Fig.8, that only after 5 years of SNF storage in the cooling pool at the reactor [7], the contribution of relatively shortlived isotopes ${ }^{106} \mathrm{Ru}\left({ }^{106} \mathrm{Rh}\right),{ }^{134} \mathrm{Cs},{ }^{144} \mathrm{Ce}\left({ }^{144} \mathrm{Pr}\right)$ to the $\mathrm{DR}_{\text {sum }}$ is still significant $(58 \%)$ at the moment, when the VSC-24 cask is put into storage. For the storage time of 6 years, the contribution of these isotopes is much smaller (it is already 45\%). Fig.9 shows the dependences of $\mathrm{DR}_{\text {sum }}$ on the storage time for SNF of WWER-1000 reactors with burnup of $40.5 \mathrm{MW} \cdot$ day $/ \mathrm{kg} \mathrm{U}$, the initial concentration of isotopes at 3 -year storage is given in Table 1 .

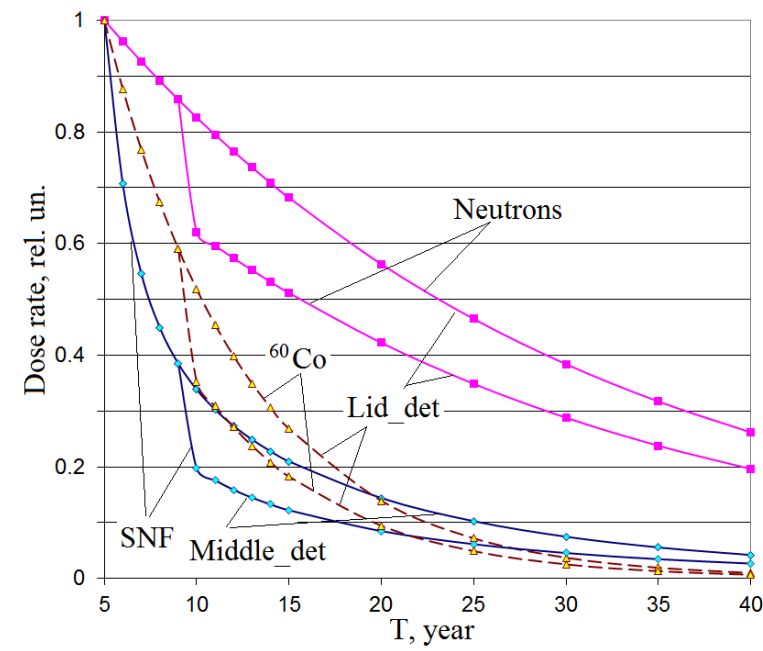

Fig.9. DR produced by SNF neutrons and $\gamma$-quanta, and also by SFA heads $\left({ }^{60} \mathrm{Co}\right) \gamma$-quanta vs the storage time, and their changes at the destruction of the fuel rod claddings

It is assumed that in the period between the ninth and tenth years of storage, the destruction of the 
fuel rod claddings occurs, which leads to a change in the SNF zone geometry and to a stepwise change in the dose rate on the cask surface. For comparison, Fig.9 shows the dependences of DR, produced by SNF neutrons and $\gamma$-quanta of the SFA $\left({ }^{60} \mathrm{Co}\right)$ heads, and their changes at the destruction of the fuel rod claddings.

\section{CONCLUSIONS}

For a non-absorbing cylindrical source, the dependences of the dose rate at the specified distances in the axial and radial directions are calculated subject to the storage time, the total activity of the emitters in the source volume being constant, with account for possible decrease of the cylinder height caused by the destruction of fuel rod claddings. Options of changes in the SNF distribution in the basket at possible destruction of the fuel rod claddings, as well as consequent changes in the radiation characteristics, are considered for the casks VSC-24 prescribed for SNF storage by dry method and used at Zaporizhzhya NPP. Simulation of two options for the SNF distribution is performed in the MCNP package: first, the height of the fuel area of all 24 SFAs in the basket is reduced twice; second, the height of the fuel area of 10 central SFAs is reduced twice, while the height of 14 SFAs, located along the perimeter of the basket, does not change.

The SNF radiation of neutrons and gamma quanta on the weather lid and the lateral surface of the cask is calculated. Actinoid ${ }^{244} \mathrm{Cm}$ is considered as the SNF radiation source of neutrons. And six main long-lived isotopes: ${ }^{90} \mathrm{Y}\left({ }^{90} \mathrm{Sr}\right),{ }^{106} \mathrm{Rh}\left({ }^{106} \mathrm{Ru}\right)$, ${ }^{134} \mathrm{Cs},{ }^{137 m} \mathrm{Ba}\left({ }^{137} \mathrm{Cs}\right),{ }^{144} \mathrm{Pr}\left({ }^{144} \mathrm{Ce}\right),{ }^{154} \mathrm{Eu}$, - are considered as the SNF radiation source of gamma quanta. The radiation from the SFA heads, caused by the induced activity of ${ }^{60} \mathrm{Co}$, is also taken into account.

It is shown that due to the specific features of radiation shield in the radial and axial directions, the destruction of all 24 SFAs leads to a significant reduction in the dose rate of neutrons and $\gamma$-radiation from ${ }^{60} \mathrm{Co}$ on the cask weather lid. This destruction also causes notable reduction of $\gamma$-radiation from six SNF isotopes at the mid-height of the cask lateral surface. The destruction of 10 central SFAs does not lead to any change in the DR on the cask surface, but can be recorded by measuring the DR produced by neutrons in the cask air ducts.

On balance, three methods of identification of the fuel rod cladding destruction from the change in the radiation of the SNF storage casks is proposed in the present paper. First, a stepwise decrease in the neutron dose rate, as compared to the calculated decrease (half-life of ${ }^{244} \mathrm{Cm}$ being 18.1 years), measured on the weather lid, indicates a change in the spatial distribution of the radiation sources in the storage basket. Second, a stepwise reduction in the measured dose rate of $\mathrm{g}$ radiation on the weather lid (half-life of ${ }^{60} \mathrm{Co}$ being 5.27 years) also indicates the fuel rods destruction. And the third, possible destruction of the fuel rod claddings can be concluded from observing the difference between the temporal character of the dose rate of g-radiation, measured on the lateral surface, and that predicted for the case of normal fuel rods (see Fig.9).

\section{References}

1. O.K. Chopra et al. Managing Aging Effects on Dry Cask Storage Systems for Extended Long-Term Storage and Transportation of Used Fuel. Revision 1, FCRD-UFD-2013-000294, ANL-13/15, September 30, 2013.

2. S. Alyokhina. Thermal state of ventilated storage container with spent nuclear fuel under normal operation // International Journal of Nuclear Energy Science and Technology. 2019, v.13, N4, p.4; p.381-398. DOI: $10.1504 /$ IJNEST.2019.106056.

3. X-5 Monte Carlo Team. MCNP - A General Monte Carlo N-Particle Transport Code, Version 5. Volume I: Overview and Theory. LA-UR-03-1987, Los Alamos National Laboratory, Los Alamos, N.M., 2003.

4. T. Sato, Y. Iwamoto, S. Hashimoto, et al. Features of Particle and Heavy Ion Transport code System (PHITS) version 3.02 // J. Nucl. Sci. Technol. 2018, v.55, p.684-690.

5. S.V. Alyokhina. Naukovi osnovy teplovoyi bezpeky sukhoho zberihannya vidprats'ovanoho yadernoho palyva: dys. na zdobuttya nauk. stupenya doktora tekhn. nauk: spets. 05.14.14 «Teplovi ta yaderni enerhoustanovky»-Odesa, 2019, 302 s. (in Ukrainian).

6. N.G. Gusev, V.E. Kovalev, D.P.Osanov, et al. Protection from radiation of extended sources. Moscow: "Gosatomizdat", 1961, $287 \mathrm{p}$.

7. I.I. Zalubovsky, S.A. Pismenetskiy, V.G. Rudychev, et al. Protective structures for storing spent nuclear fuel from the Zaporozhye NPP // Atomic Energy. 2012, v.112, Issue 4, p.261-268.

8. V.G. Rudychev, M.O. Azarenkov, I.O. Girka, et all. Contribution of radiosondes to heat release in the process of SNF dry storage // Problems of Atomic Science and Technology. Series "Physics of Radiation Effect and Radiation Materials Science". 2017, N2(108), p.91-96.

9. V.M. Kolobashkin et al. Radiation Characteristics of Spent Nuclear Fuel. Handbook. Moscow: "Energoatomizdat", 1983, p.167-169.

10. RSIC Computer Code Collection, OGRE, GeneralPurpose Monte Carlo Gamma-Ray Transport Code System, CCC-46, Union Carbide Corp., Nucl. Div., Oak Ridge Natl. Lab. (updated July 1981).

11. Shielding analysis of dual purpose casks for spent nuclear fuel under normal storage conditions // TaeMan Kim, Myung-Hwan Seo et al. Nucl. Eng. and Technol. 2014, v.46(4), p.547-556.

12. V.G. Rudychev, I.O. Girka, Y.V. Rudychev, et al. Change of radioactive waste characteristics at their processing and storage at nuclear power plants //Problems of Atomic Science and Technology. Series "Nuclear Physics Investigations (64)". 2015, N3(97), p.83-88. 
13. D. Reilly, N. Ensslin, H. Smith. Los Alamos National Laboratory., \& U.S. Nuclear Regulatory Commission // Passive Nondestructive Assay of Nuclear Materials. Washington, DC, USA, 1991.

14. P.M. Rinard, G.E. Bosler, and J.R. Phillips. Calculated Neutron Source Spectra from Selected Irradiated PWR Fuel Assemblies. USA: Los Alamos National Laboratory; 1981, LA-9125-MS.

15. V.G. Rudychev, N.A. Azarenkov, I.O. Girka, Y.V. Rudychev. Efficiency of various materials application for radiation shielding at transportation and storage of spent nuclear fuel by dry method // Problems of Atomic Science and Technology, Series "Physics of Radiation Effect and Radiation Materials Science". 2020, N2(126), p.64-70.

16. V.G. Rudychev, N.A. Azarenkov, I.O. Girka, Y.V. Rudychev, et al. Patent Ukrayini N120480 vid 10.19.2019 Byul.N23 (State Register of Patents of Ukraine), Sposib kontrolyu bezpeky zberihannya vidprats'ovanoho yadernoho palyva sukhym metodom. (in Ukrainian).

\title{
ИДЕНТИФИКАЦИЯ РАЗРУШЕНИЯ ОБОЛОЧЕК ТВЭЛОВ ПО ИЗМЕНЕНИЮ ИЗЛУЧЕНИЯ КОНТЕЙНЕРОВ ХРАНЕНИЯ ОЯТ
}

\author{
В.Г. Рудычев, Н.А. Азаренков, И.А. Гирка, Е.В. Рудичев
}

Для контейнеров VSC-24, используемых при хранении ОЯТ сухим методом, рассмотрены два варианта изменения распределения ОЯТ вследствие возможного разрушения оболочек ТВЭЛов, ведущего к изменению излучения вне контейнера. Аналитическим и численным моделированием в пакете MCNP исследовано влияние уменьшения высоты вследствие разрушения ТВЭЛов всех 24 OTВС и 10 центральных ОТВС на внешнее излучение. Показано, что разрушение 24 ОТВС приводит к значительным уменьшениям мощности дозы нейтронов и $\gamma$-излучения от ${ }^{60} \mathrm{Co}$ на погодной крышке контейнера, а для $\gamma$-излучения от изотопов ОЯТ - на середине высоты боковой поверхности контейнера. Разрушение 10 центральных ОТВС определяется только изменением излучения нейтронов в воздухозаборнике контейнера.

\section{ІДЕНТИФІКАЦІЯ РУЙНУВАННЯ ОБОЛОНОК ТВЕЛІВ ЗА ЗМІНОЮ ВИПРОМІНЮВАННЯ КОНТЕЙНЕРІВ ЗБЕРІГАННЯ ВЯП}

\section{В.Г. Рудичев, М.О. Азаренков, І.О. Гірка, Е.В. Рудичев}

Для контейнерів VSC-24, які використовують для зберігання ВЯП сухим методом, розглянуто два варіанти зміни розподілу ВЯП внаслідок можливого руйнування оболонок ТВЕЛів, що спричиняє зміну випромінювання поза контейнером. Аналітичним та чисельним моделюванням у пакеті MCNP досліджено вплив зменшення висоти внаслідок руйнування ТВЕЛів всіх 24 ВТВ3 та 10 центральних ВTВ3 на зовнішне випромінювання. Показано, що руйнування 24 ВТВ3 спричиняє значне зменшення (стрибок) потужності дози нейтронів і $\gamma$-випромінювання від ${ }^{60} \mathrm{Co}$ на погодній кришці контейнера, а для $\gamma$-випромінювання від ізотопів ВЯП - на середині висоти бічної поверхні контейнера. Руйнування 10 центральних ВТВ3 визначається лише з випромінювання нейтронів у повітрозабірнику контейнера. 